\title{
Selective control of photoassociation of Yb2: by theoretical study
}

\author{
Junxia Cheng ${ }^{1}$, Hong Zhang ${ }^{2}$, Xinlu Cheng ${ }^{2}$, Jia Wang ${ }^{1}$, and Shenjiang $\mathrm{Wu}^{1}$ \\ ${ }^{1}$ Xi'an Technological University \\ ${ }^{2}$ Sichuan University
}

August 18, 2020

\begin{abstract}
The selective control of photoassociation of Yb2 molecule is investigated in theory. Based on ab initio to rationalize FranckCondon filtering, the optimal target states of photoassociation have been obtained. That correspond to vibrational transition levels from $\mathrm{X} 1 \Sigma+\mathrm{g}$ to excited state $(\mathrm{A} 1 \Sigma \mathrm{u}+, \mathrm{B} 1 \Pi \mathrm{u}, \mathrm{C} 1 \Sigma \mathrm{u}+, \mathrm{D} 1 \Pi \mathrm{u})$ are $\mathrm{v}^{\prime}=23,50,55$, and 0, respectively. The proposed laser drive transitions to target states for association process at wavelength $\mathrm{A} 1 \Sigma \mathrm{u}+$ : $464.7 \mathrm{~nm}, \mathrm{~B} 1 \Pi \mathrm{u}$ : $373.1 \mathrm{~nm}, \mathrm{C} 1 \Sigma \mathrm{u}+$ : $361.8 \mathrm{~nm}$, D1Пu: $339.1 \mathrm{~nm}$ are determined. By using quantum wave-packet dynamic methods, we calculated the yields with time evaluation for the selected target states. Interacting with a resonant laser pulse, the projections of time-dependent wave

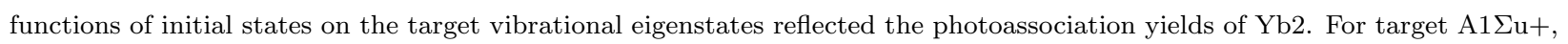
using gaussian pulse made the value of v' $=23$ up to $97 \%$ at $725 \mathrm{fs}$. After a laser pulse, that the positive chirp promotes the yield of projection of vibrational states to increase, but the negative chirp inhibits it decrease. For D1Пu state, when laser intensity is $1.0 \times 1014 \mathrm{~W} / \mathrm{cm} 2$, not only the purity is high but also the yield is high reached $99 \%$ of target state v'=0 at $1570 \mathrm{fs}$. That is to say, by changing the laser parameters and pulse shapes, it could much easier control the photochemical along our desired direction. These conditions will provide an important reference and suggest a scheme for a feasible photoassociation for further experimental and theoretical researches.
\end{abstract}

\section{Hosted file}

manuscript.doc available at https://authorea.com/users/351849/articles/476304-selectivecontrol-of-photoassociation-of-yb2-by-theoretical-study 